\title{
Sheltered in Safe Hands - A Study on the Usage and Effectiveness of 'Kavalan' SOS App among Women in Tamil Nadu
}

\author{
Dr.N. Tamilselvi ${ }^{a}$, Leo Getrude ${ }^{b}$ \\ ${ }^{\mathrm{a}} \mathrm{HOD}$, Department of Visual Communication, The Quaide Milleth College for Men, Chennai. \\ E-mail: tamilselvishahul@gmail.com \\ ${ }^{\mathrm{b}}$ Assistant professor, Department of Visual Communication, Kumaraguru College of Liberal Arts and Science, \\ Coimbatore. E-mail:leogertrude@gmail.com
}

Article History: Received: 11 January 2021; Accepted: 27 February 2021; Published online: 5 April 2021

\begin{abstract}
As we progress towards digital era, using smart phones to ensure safety of citizens, especially women is seen as a great relief. After the gory crime of Delhi gang rape in 2012, the government has introduced various safety measures to protect women, one of which is the development of safety apps. Though there are many safety apps for women, this study focuses on 'Kavalan' app, which was launched in 2018 by Tamil Nadu police to ensure women safety. This mobile application seems to have a wide reach as soon it was launched and efforts have been taken by the police department to make sure that citizens are aware of the mobile app. The present study focuses on few questions like the reach of the app in rural areas, and women who do not know to use technology and tries to find the answer through survey and in-depth interviews.
\end{abstract}

Keywords: Safety Apps, Women Safety, TN Police, Smartphone Solutions, ICT for Women.

\section{Introduction}

Women are worshipped as goddesses by people in India since ancient times. On the contrary the number of crimes against women also keeps increasing every year. Women are exposed to sexual violence even at the age of 80 and even children are not spared to the gory crime of rape. Threat to safety of women has become a norm nowadays and research across the globe points out various reasons for the increasing crime against women which includes women getting exposure to every field of life. Now women are seen working in all areas equal to men and that includes even working late hours at night. In such a scenario, safety of women is a big question, considering the increasing number of crimes that happen against women. Though the patriarchal mindset of the society has changed a lot in the past decade, it has still not helped in treating women equally. There are different ways in which safety of women is still a threat, which include eve teasing, sexual harassment, rape and domestic violence. Most of the crimes against women go unreported because of family and social pressure. Hence the number of reported cases against women is considerably less than the number of actual crimes happening in the country. Considering the trauma that a sexual violence can bring in the mind of a woman and also with the slow pace of Indian judiciary system, it is often agreed that prevention is better than cure.

Women are under constant fear of being assaulted with crime against them and that challenges their physical and mental health. The unhealthy environment for women in India and the increasing crime against women creates a sense of fear which makes them dread the idea of going out alone. This can have many effects in the sociological and economic aspect of the society. As an effective solution to this problem and also to trigger the confidence level of women by promising them their freedom and safety, technology was put into practice. Many companies have designed a number of mobile applications which promise women safety. These mobile apps are designed in such a way that they give a sense of empowerment to women and assure them their safety by keeping their close contacts informed about them just by a click of a button.

Though empowerment of women is given lot of importance these days, it cannot be denied that sexual harassment and domestic violence are becoming a silent norm of the society and that silence has become normal. To break the silent and also like a whistle blower, the \#MeToo movement has made it clear that women have the power to defend themselves through the usage of technology. Their smart phones gives them the ability to express their feelings or suffering instantly through social networking sites. It has made them possible to create a whole movement to voice out sexual harassment against women. It acts as a tool for them to fight against the age old patriarchal system which is still present in the society. The National crime records Bureau states that there is continuous increase in the crime rate that are committed against women like rape, molestation, kidnapping, domestic violence, child trafficking and so on. Apart from the trauma that women undergo after a heinous crime, they are also not believed by the society and the victims are always blamed. In such a scenario, women activists who come up boldly and voice out against the harassment done to women, which has the capacity to trigger a whole movement online are also putting their everyday life under threat. 
Safety of women is also a serious threat when they travel out. Unlike olden days women now step out of their household for various jobs. They work equally competent to men in all fields which involve travelling at night too. Though they are provided with travel facility by the company where cabs pick them and drop them at their destination, safety of women is still a big question and complaints of sexual violence and rape continue to increase. The recent taxi services like Ola and Uber have also introduced tracking system and SOS button in their mobile App, after many complaints against the drivers of these taxi aggregates. Hence safety of women always remains as an unsolved problem. Nevertheless technology is being sought for help often in fighting crime against women. For example, Instillation of a number of CCTV cameras in subways, main roads, streets etc and the help line numbers available to report sexual and domestic violence against women and children are major steps taken by the government to reduce crime to a minimum level. Apart from this many private organizations also try their best to fight crime against women by setting up of women's grievance redressal cell as part of the new laws enforced to ensure women safety. Even the taxi aggregates have also introduced SOS app in their mobile applications so that the passengers can be kept track of by their close relatives. It also allows them to share the ride details, like the name of the driver, vehicle number, boarding time into the vehicle and also the facility to track the vehicle in GPRS along with a panic button for emergency.

While so many measures are being done to combat sexual harassment and violence against women, there still seems to be an alarming increase of this crime, especially in a country like India which glorifies womanhood. To address this issue, the state governments of many states have again sought the help of technology. It was felt by the government that an effective mobile application which can make the citizens of the country reach the police department by just clicking a button can save a lot of time in reaching out to those in danger and also help in reducing the crime. So assuming that technology can be effectively used to help those who are in danger or in dangerous situation to seek help from their family, friends or the state, many mobile applications were developed and they are being used by many citizens of the country. This empirical study aims to study the usage and success of 'Kavalan' mobile application in curbing violence against women.

\section{Objectives of the Study}

- To find out how effectively technology is used to curb violence against women.

- To explore the reach and usage of 'Kavalan' mobile application as an effective tool for safety of women through survey and in-depth interviews.

- To examine the success rate of 'Kavalan' mobile application among rural and under privileged women.

\section{Review of Literature}

Nicole Westmorland et al from Durham University and Durham centre for research in violence and abuse (2013) discussed on women's safety using mobile applications in their book 'Protecting Women's Safety' where the usage of Smartphone apps in relation to domestic and sexual violence was explored.

The World Health Organization in the year 2013 generated a report based on the discussion on women safety held at Geneva on 'Global and regional estimates of violence against women'. It discussed on the prevalence and health effects of intimate partner violence and non-partner sexual violence, and estimated that $35 \%$ of women worldwide have experience either physical or sexual violence by intimate partner and also through non partner sexual violence. The report also talks in detail about the effects of violence on the reproductive and mental health of women.

In their book "Surveillance studies and violence against women", Mason, C and Shoshana Magnet, (2012) discussed about surveillance technologies where they have discussed the theoretical framework that throws light on the challenges that new technologies gives to movements that are work for violence against women. This research work specifically addresses the impact between surveillance technologies and violence against women. Mason and Shoshana Magnet also propose effective solutions and consider the ways through which these technologies are used in an imbalanced manner and used to criminalise marginalized group. The study has placed violence against women at its core and has tried to study the concerns related to surveillance technologies.

In the book 'Intimate Terrorism and Technology: There's an App for that', Justine A. Dunlap (2012) opined that technology is used in circumstances of intimate terrorism. The study analyses how technology is used as a tool to take control over a victim and force her to yield to the perpetrator's desire. It also gives an overview of the laws and legal systems and whether they are at par with the rapid advancement of science and technology. The usage of GPS in tracking terrorists was also analysed and discussed in this study and gives good insight on the legal system that is present now and how it can be modified as per need of the hour. However Elliott, J. and 
Mc Cartan K. in their book 'The Reality of Trafficked People's Access to Technology' published in the Journal of Criminal Law (2013) said that the advancements in science and technology and the perpetrators access to it might cause them to escalate or adapt to their offending behaviour.

In a study conducted in the United States which focused on relationship between domestic violence and Information technology, Diamond et al (2011) found that there existed a relationship between potential harm which was termed as continued abuse and benefit. The advancements in the mobile phones and software capabilities, has made cell phone and its usage a mandatory system which has to be incorporated into our everyday lives (Dennison, L., Morrison, L., Conway, G., \& Yardley, L., 2013). In the study 'Transforming women's livelihoods through mobile broadband' conducted by Qualcomm Wireless Reach TM, Vital Wave, and GSMA in the year 2014, provides insights in health of women through continuous use of smart phone applications. The findings of the report say that App developers may wish to carry a number of features and characteristics which can make the app unique and how it can have an impact on health of women. A report by Vodafone on Connected Women conducted (March, 2014), talks about how smart phones can connect to women's economic and social empowerment. The study reported that cell phone usage has empowered women in many ways and have also made them expose to literacy, banking and health. It has also made them rise new business opportunities.

\section{Overview of Kavalan SOS}

Kavalan mobile application was initiated by the Government of Tamil Nadu as an SOS app, as part of the mobile control room initiative. This mobile application is developed by Amtex systems and by using this mobile application people of Tamil Nadu can seek the assistance of Tamil Nadu police in cases of emergency. These emergency situations also include natural disasters such as flood, earthquake etc apart from crimes like eve teasing, kidnapping, molestation, domestic violence and sexual violence. Using the Kavalan SOS, those in danger can seek the assistance of the police department directly and this can facilitate policemen to take action swiftly. The mobile application was originally designed keeping women and elderly people of Tamil Nadu in mind. Those in danger can use this app, whenever they feel violated or threatened or in any dangerous life threatening situation. This SOS can help them in getting help from police at the earliest, irrespective of where they are. The app can be easily downloaded from Google play store for android users and it can be downloaded from apple store for iOS platforms thus enabling users of both platforms to reach out to help in times of danger.

\section{How the Mobile Application Works}

Anyone can start using the Kavalan SOS by just registering the basic information after downloading it from Google play store or apple store. The basic information include name, mobile number, date of birth, gender, email address, residential address and details of name and address of any two close relatives or neighbours or friends who can be contacted for emergency. These emergency contacts are preferred to be living in the same city as that of the user. Apart from two emergency contacts provision are also given to add a third contact to the emergency contacts. After the necessary details are filled, the user receives an activation code on the registered mobile number after which the application appears on the home screen of the mobile phone and it is ready to use. In emergency situation, the user can just press the SOS button on the home screen and immediately a countdown of 5 appears. After 5 seconds, the location of the user is automatically sent to the police control room. A short video from the back camera of the mobile phone is also automatically recorded and sent to the police control room to enable tracing the location or the situation the user is currently in. Within a minute or less, the police / Kavalan team will contact the user. The location of the user is also shared to the emergency contacts given at the time of registration as an SMS alert when the SOS button is pressed.

While it appears to be very simple and easy to use, this mobile application seems to have many pros and cons in its usage. Though the application was introduced in the year 2018 in the month of June, it was only after the rape and murder of the 26 year old veterinary doctor in Hyderabad that the app has received many downloads. Now the mobile application has crossed more than one million downloads. There are also initiatives by the police department promoting the usage of Kavalan app by making an intensive campaign advising citizens to make use of the app. It was reported that after the rape and murder of the Hyderabad doctor and the increased intensive campaign by police men, an average of ten thousand people download Kavalan SOS app.

\section{Data Privacy}

While the mobile application assures safety of citizens by just clicking a button, data security and piracy seems to be an unanswered question for many of its users. People have expressed their hesitation in downloading Kavalan app fearing misuse of data or data privacy. Users have questioned on why the mobile application should 
have access to their phone gallery and why they must also register their date of birth. Apart from this there are also technological issues in downloading the app and the non functioning of app during emergency situations.

Social worker Fathima Muzzafer (2019) has registered her concern of data privacy in downloading the app by saying that allowing access to phone call or device location would not be a problem but allowing access to record audio, and access storage of the media files in the phone gallery and also allowing the app to access contacts of the phone are questions of serious concern over data privacy and safety. She also pointed out that the mobile application cannot be used without giving access to all these information. This is also one of the reasons why many users are not willing to download the application, though it is designed for safety purpose.

\section{Methodology}

To find out whether technology was really helpful in curbing sexual violence against women, both qualitative and quantitative methods were adopted for this study. Data was collected through surveys conducted online using Google forms which included minimum details from the respondent and how these safety apps have served the purpose of women safety. It was also intended to find out if technology can really be an effective way to keep crime against women under control. Data was collected from 150 respondents randomly who are native of Tamil Nadu through survey. The researcher also conducted in depth interviews from government officials and general public. This qualitative analysis was done to validate the data collected through survey method and also to understand the pros and cons of using technology to reduce crime.

\section{Findings}

Data was collected from 150 respondents and the following results were found. To understand the data in a better way, first the quantitative data is given under various parameters used to collect the data, followed by interpretations collected from in-depth interviews, wherever possible.

\section{Gender}

\section{Gender}

150 responses
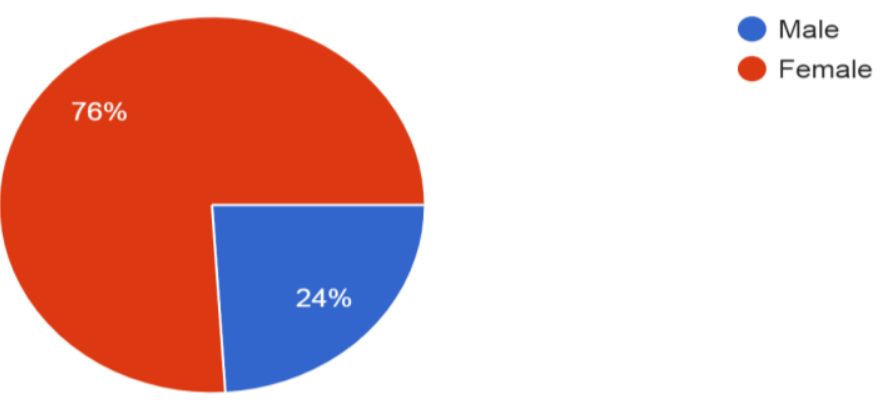

\section{Figure 1}

To find out the effectiveness of the app, both male and female respondents were included in the data. However the participation of female respondents were more compared to male respondents. Questions were specifically designed for both the genders and whenever the question was not applicable to them, the respondents were simply asked to mark NA to that question. Out of the 150 responses collected for the survey, 76 percent were female and 24 percent were from male respondents.

\section{Age}

The age group was classified based on school going population, college group and working class which was further classified into middle age and upper middle age. Majority of the respondents were from the middle age ranging from 36 to 45 years, who constituted $44.7 \%$ of the data, followed by the age group $26-35$ who were $23.3 \%$ of the sample. Respondents from age group $15-18$ constituted the third major population of the sample contributing to $16.7 \%$ followed by age group $19-25$ with $11.3 \%$ of the sample. Respondents above the age group of 45 were the least contributing to merely $4 \%$ of the data. 


\section{Age Group}

150 responses
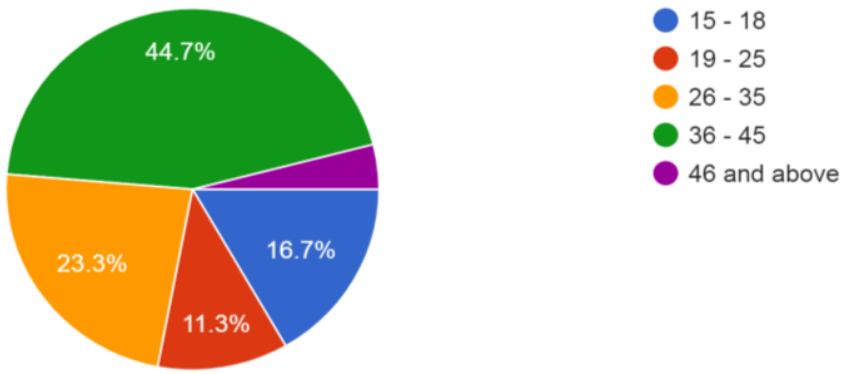

Figure 2

\section{Awareness}

When asked whether the respondents were aware of the safety mobile applications for women, $68 \%$ of the respondents said they were aware of few apps while $32 \%$ of the respondents said that they are not aware of any such safety applications in mobile phones.

\section{Are you aware of the safety apps for women?}

150 responses

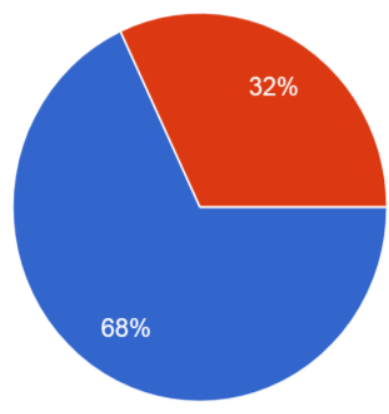

\section{Figure 3}

Many respondents also mentioned names of other mobile applications such as Safety Pin, VithU, Nirbhaya, Raksha, Bsafe etc apart from Kavalan SOS.

\section{Usage}

After knowing the awareness of the mobile App, respondents were asked if they were using any mobile application. This question was directed only to the female participants and hence male respondents were asked to mark NA to this question. Out of the $76 \%$ female participants, only $21.3 \%$ used SOS app while $58 \%$ did not use the app.

If female, Are you using or have used any of the safety apps?

150 responses

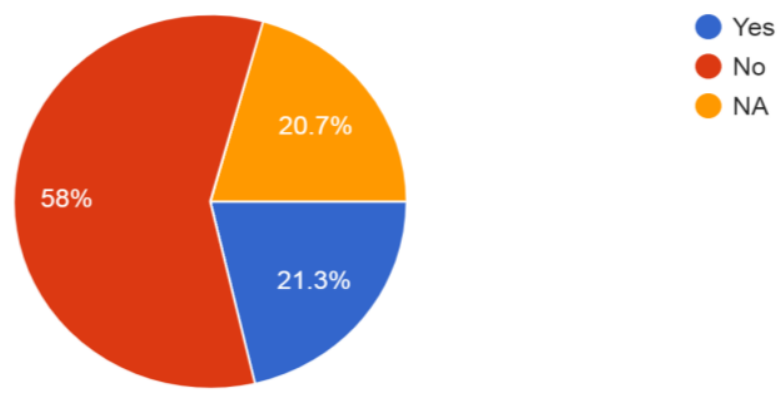

Figure 4 
In order to find out why the respondents were not willing to use the mobile app for their safety though they are aware of it, they were asked to respond on their own in one sentence or phrase mentioning the reason for not using the app. The results showed that $49 \%$ of the population was not aware of the existence of any safety apps using smart phones, and 9.3\% declared that they have technological issues in downloading the app. An equal number of respondents (9.3\%) mentioned that they are simply not interested in using the SOS while 3.3\% mentioned that the app is not user friendly. An interesting revelation from this question as that $12.7 \%$ of the female respondents in the sample did not believe that technology can help in giving them protection.

\section{If you are not using the safety app, What is the reason for not using it?}

150 responses

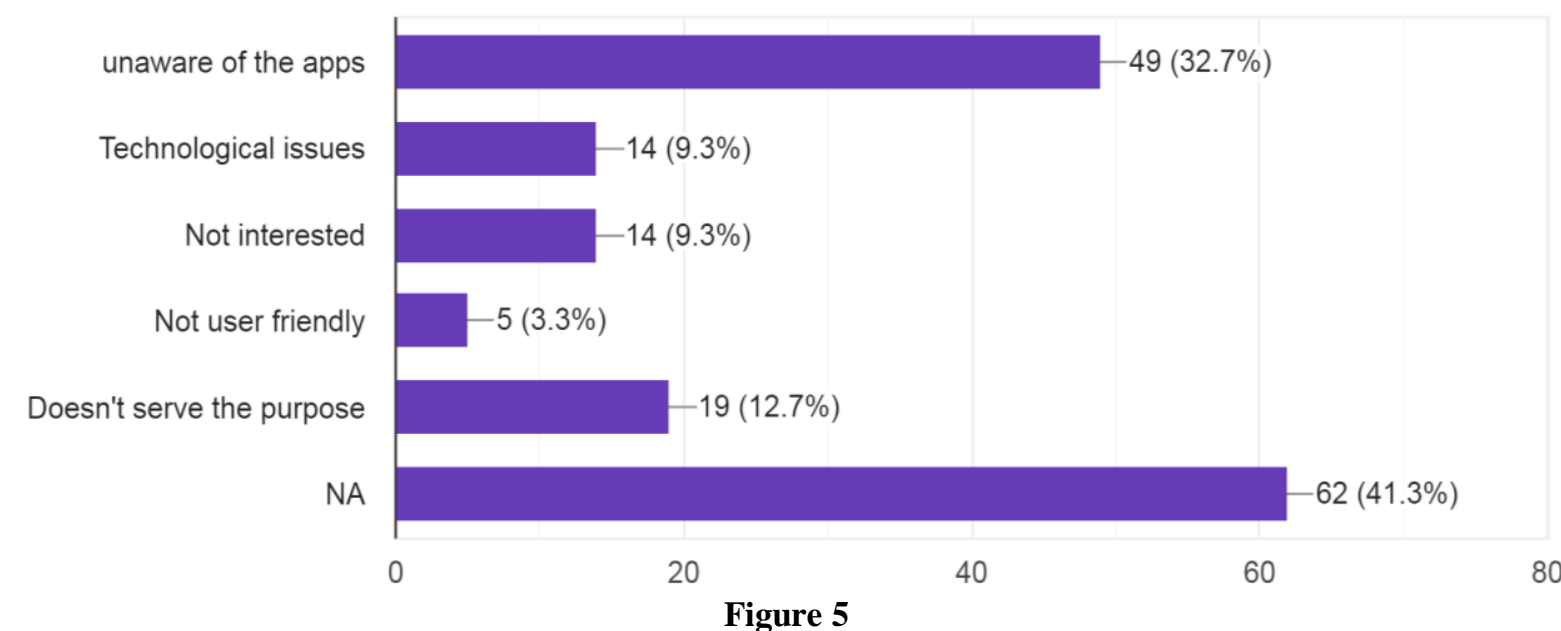

Another question directed to male respondents was to find out if they believe that the development of SOS can help in reducing crime against women and they were asked if they had recommended its usage to their friends or family. The results showed that out of the $24 \%$ of male respondents $29 \%$ of the respondents have recommended the usage of the SOS to their friends and family while $18.7 \%$ of the respondents did not recommend the app to their family or friends.

\section{If male, have you recommended your friend / family / colleague to use the safety apps available for women?}

150 responses

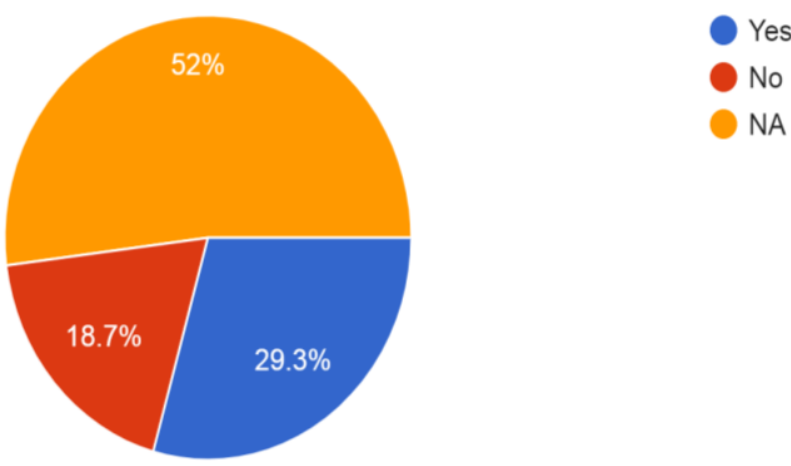

Figure 6

Finally when both male and female respondents were asked $\mathrm{f}$ they believe that technology can help in fighting against crime, more than half of the respondents believe that using technology can really be helpful. While $38 \%$ of the samples were speculative about the SOS app, $8.7 \%$ of the respondents clearly stated that using technology cannot help in reducing crime against women. 


\section{Figure 7}
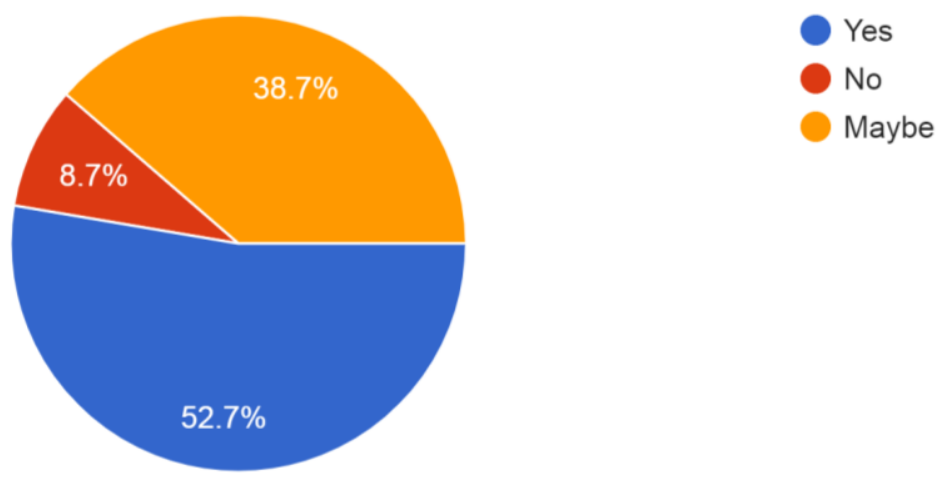

To validate the data collected through survey, the researcher also conducted in-depth interviews with Assistant commissioner of Police and also with few respondents. The main objective of the qualitative analysis was to know the purpose of creating the mobile application and whether this mobile application has served women of all sections in the society. Mr. Arockiya Prakasam, Assistant Commissioner of Police at Vadapalani (Chennai) division was interviewed for the purpose. He opined that the Kavalan Safety app or SOS is the best initiative taken by the government to reduce crime against women to a great extent. He said that lot of awareness programmes are conducted on the usage of the mobile application and its effectiveness, in schools, colleges and places where large crowd gather like malls, shopping centers etc, market places and busy streets. There were also news articles written about Kavalan SOS in both Regional and National newspapers and awareness about the mobile application is given in almost all television news channels and radio FM stations. Inspite of such huge awareness being made in all possible ways, Mr. Arockiya Prakasam said that it is quite shocking to note that so many people are still not aware of any such safety apps and that too in the educated section of the society. Answering to questions on the effectiveness of Kavalan SOS, Mr. Arockiya Prakasam said that this app was effective in reducing crime and to reach out to people during cases of emergency. He cited examples of situations where a woman sought the help of police using kavalan SOS when someone in the bus tried to misbehave with her. Police reached out to her help and the culprit was arrested in the next bus stop itself where police were waiting for him after the message was sent to the control room to trace the bus and arrest the accused. He also said other examples and cases where people seek their help when they are locked inside home by accident and not able to reach anyone and seek their help for rescue. However he also mentioned that there are also many false alarms raised either by not knowing how to use the app or also to check if the app is in correct working condition. He said that such false alarms are wasting the time of police but still they do not complain about it as people are also new to the app and curious about its working.

When asked about how this app has been helpful for women to rescue themselves from sexual violence and rape, Mr. Arockiya Prakasam pointed out that rape cases are never a threat to India as India is the safest country for women and especially Tamil Nadu has lowest number of recorded rape cases which constitutes to only $0.5 \%$ of the crime against women. Hence the Kavalan SOS was not designed to save women from the crime of rape but to offer protection from other crimes like eve teasing, domestic violence etc which he claims is happening at a higher rate than rape. He also added that anyone in danger can seek help through Kavalan SOS but this app was not designed for sexual harassment alone. He believes that "rape can never happen between a single man a single woman" as women are naturally gifted with protective defense mechanisms and if they do not want to get raped they can easily escape the perpetrator. He also believes that rape is only consensual sex which has gone wrong between two partners and it is registered as a complaint only the relationship goes wrong with the two. Hence he believes that Kavlan SOS is designed for more heinous crimes than rape as rape according to him is a misguided word for consensual relationship and sex that has gone wrong. However he agrees that only gang rape is possible where one woman is raped by more than two or three men and rape between a single man and single woman is possible when the woman is spiked or is unconscious. He also felt that rape under such a circumstance cannot be technically termed as rape as the person doing it will not be able to experience sexual pleasure as the woman is unconscious. Hence he strongly believes that Kavalan SOS is for women to reach out to the police in genuine circumstances of danger like eve teasing, domestic violence etc. 
When asked about the safety issues and data privacy related to downloading Kavalan SOS, the Assistant commissioner, Arockiya Prakasam said that people should believe in police department first and treat them as their friend. He said that any data with the government cannot be mishandled and he opined that people are willing to believe in millions of other mobile applications and allow access to their phone gallery like location, gallery etc, but they do not believe in police department when it comes to their safety. However many colleges girls and school children interviewed for the same opined that they do not feel comfortable sharing the data with police as it asks for access to phone gallery and photos and videos. They have registered their mistrust in police as they have read in newspapers that many rape cases happen in the police station too. Considering the thoughts of Assistant Commissioner Arockiya Prakasm on Rape, it is evident that young women do not feel comfortable to allow access to Kavalan SOS to reach their phone gallery with photos and videos as they feel it can be misused.

The Assistant Commissioner also suggested that data stored in apple store is very safe compared to android. Hence people can purchase their mobile apps from apple stores to ensure safety of data. When asked whether Kavalan SOS downloaded from android Google play store is not safe, he affirmed that any data with the government is very safe and no one can mishandle it and it is only left to the people to believe in them. He said he is also giving awareness talks about Kavalan SOS in many schools and colleges and he sees a number of positive responses among the audience.

While the number of downloads and reach of the Kavalan SOS mobile application is increasing, it is also mandatory to understand which segment of the society is this application targeted to. It also gives rise to other questions like whether safety of women can be guaranteed only to those who have knowledge to use the technology and what about the safety of children who do not have access to android phones in school. The safety of women in the marginalized sector of the society who might have an android phone and do not have any idea about how to use the app is also an important point to consider as they constitute a large segment of the society. When questioned about the reach of Kavalan SOS among women from the marginalized section of the society and from rural women, Mr. Arockiya Prakasam agreed that no such awareness or steps to create awareness is initiated by the government apart from what is being told in the news or FM and if they get a chance to listen to it then they might know about the app. When the researcher asked that even if they are aware of the app they might still not know how to download the app or use it and so to overcome this whether the police department reached the help of the any civil societies, the Assistant Commissioner replied negatively saying no such help is sought from any NGO's. He opines that women from the under privileged or marginalized section of the society can take care of themselves and are really brave and they also affirm that they can take care of themselves. Whereas it is only the middle class women who go to work need protection. Regarding the question on the reach of the app to the rural regions of the society, he said that the app is famous only among the urban regions and no steps are taken to reach the rural sector as it is very costly and will involve lot of fund to establish the set up. When the central government is ready to spend 1000 crore on Nirhaya fund, it is shocking to hear the state government say that there is not fund to develop or extend the facility. When the Assistant Commissioner was asked about the same said that the funds are not available and the Nirbhaya fund will not reach them. When questioned further why it will not reach the government he opined that it might be misused in wrong hands and refused to talk further on this.

The researcher further questioned on how the app or technology can be an effective tool to curb crime against women, to which Mr. Arockiya Prakasam replied that no technology can help in saving women against all this crime unless everyone in the society is determined to be self controlled and not disclose too much information to strangers whom they meet online. He opined that technology has given rise to more crimes and it is only through self control that women can be safe. He also said that with the installation of CCTV cameras crimes are now reduced to a great extent and technology was helpful in that way. When questioned about safety of children he agreed that the app cannot be used by children as schools do not allow children to carry smart phones and neither do parents allow.

There are devises available which can be worn as a bracelet or chain by anyone including elders and kids which functions exactly like the SOS apps. By pressing a knob or button in the device emergency contacts are triggered with notification as SMS alert or phone call saying that the person is in danger. It also sends the location of the person wearing the device to enable tracking using GPRS. When asked whether children can be given such device by the government using the Nirbhaya fund, the assistant commissioner said that developments of such devices are very costly and the Nirbhaya fund cannot be used and the government cannot take up all the responsibility. He opined that parents must also educate their children about the pros and cons of technology and ensure their safety without blindly trusting others. He said that the child helpline is an effective way for children to reach out to them. when asked whether any children have reached out to them and whether 
they have saved any, he replied saying that less number of calls are received from children, however neighbours and well wishers do call the child helpline and report them about domestic violence that children face and they have also rescued few children based on the complaints received through the help lines.

\section{Conclusion}

Previous studies on safety apps say that safety of data is a question of concern in using these SOS effectively by the users. Technologists who work in close association with the app also affirms that the safety of the data is a question of concern as data are maintained by a private party. When a user registers for downloading the app, he or she has to provide two alternate numbers with location access and details of residence address. When so much data is given it is unnecessary to share details like date of birth and photo and also access to media files in phone device. When the number of downloads of the app keep increasing then the data will also become huge and pose a serious threat of data privacy where data can be easily mined and used for various purposes. Technologists have suggested that the app has to be designed in such a way that there is no need for the user to allow access to media files and still be able to use it effectively. Since the data is collected here for the purpose of safety, it is enforced by law and the agency is exempt from any privacy laws. Hence it is the responsibility of the police department to take adequate measures to ensure data safety and keep information fed to the agency is secure.

However police department says that contact details to be given are only optional so that they can be alerted that the person is in danger and after they received many questions about data safety, the app was modified a little where photo and date of birth are not made compulsory to register to the app. However it still asks for access to media files which many women and men are reluctant to given access to.

Though there are many mobile applications designed for safety of women by the initiative of both the government and also few corporate, it is significantly important to note that such mobile applications are only accessible by the elite and / or the educated sector of the society. Women belonging to poor and marginalized section of the society have no access to such facilities and the government has not taken enough steps to reach them either by themselves or through the help of civil societies. While many women self help groups and civil societies who work to reduce crime against women will be willing to create awareness among the women who do not know to use the app, it is surprising to note that the government has not reached them yet or has not even thought about reaching this particular section of the society.

Data privacy and safety is another major drawback of the Kavalan SOS as it is declared from technologists who work at the back end of the app saying that breach of data is possible and such huge data can be misused in many ways if leaked outside. On the other hand the government only asks its citizens to just trust them on data safety. Still the question of giving access to phone media files is a big question among the citizens, while the police department says that the app can function effectively only if access to media files is given. When the safety of women is sought through the help of technology it is really sad to note that the huge funds available for women are not utilized to take this SOS app to the rural regions of the country. When safety of women is promised it has to include safety of every women irrespective of whether they are urban or rural and the government has failed to keep this in mind while creating awareness about the app.

Furthermore citizens believe that technology can be effectively used to curb crime against women while the government believes that though technology is used it is in the hands of the citizens to ensure safety for themselves. It is also believed that rape is not a heinous crime and it happens only with consent and rape is reported only when this consensual sex goes wrong. Such misconception about rape and victim blame theory still exists in the society which is reflected from the thoughts of the assistant commissioner. These are the people to whom people immediately rush for justice and help and when they have such a mind set it is alarming to know how a women will be believed if she reports a sexual crime done to her.

Apart from giving awareness to the society it is also mandatory that awareness should also be given to people at the top level to understand the nature of a crime and also to act swiftly and reach to those in need. When technology is the future and when citizens of the society believe that they can use technology to safe guard themselves against crime and when they also believe that they can reach out to the police immediately when in danger, it is the duty and responsibility of the officials to assure the safety and that safety has to be for every section of the society rather than limiting it to only urban folklore and not reaching out to the rural sections for lack of funds. 


\section{References}

1. Dennison, L., Morrison, L., Conway, G., \& Yardley, L. (2013). Opportunities and challenges for smartphone applications in supporting health behavior change: qualitative study. Journal of Medical Internet Research, 15(4): e86.

2. Dimond, J.P., Fiesler, C. \& Bruckman, A.S. (2011). Domestic violence and information communication technologies. Interacting with Computers, 23(5): 413-421.

3. Elliott, J., \& McCartan, K. (2013). The reality of trafficked people's access to technology. Journal of Criminal Law, 77(3), 255-273.

4. Dunlap, J.A. (2012). Intimate terrorism and technology: There's an app for that. University of Massachusetts Law Review, 7(1), 10-39.

5. Mason, C.L., \& Magnet, S. (2012). Surveillance studies and violence against women. Surveillance \& Society, $10(2), 105-118$.

6. Nicole W., Mariann H., (2013). Protecting Women's Safety? The use of smart phone apps' in relation to domestic and sexual violence. Durham Centre for Research into violence and abuse, Durham University.

7. Portio Research (2011). Portio Research Mobile Factbook 2011. Chippenham, UK. Retrieved from http://www.portioresearch.com/Portio\%20Research\%20Ltd\%20Mobile\%20Factbook\%202011.pdf

8. Qualcomm Wireless Reach, Vital Wave, and GSMA. (2014). Transforming women's livelihoods through mobile broadband. Report, February 2014. Available at: http://www.qualcomm.com/mwomenreport

9. Vodafone. (2014). Connected women: How mobile can support women's economic and social empowerment. Report, March 2014.

10. World Health Organization. (2013). Global and regional estimates of violence against women: prevalence and health effects of intimate partner violence and non-partner sexual violence. Geneva: World Health Organization

11. http://www.mappsafe.com/blog-1-feb-14-three-reasons-why-mobile-technology-will-reduce-violenceagainst-women 